\title{
Comparability Assessments of Process Changes Made during Development of Anti-Idiotype Vaccine
}

\author{
Kathya de la Luz-Hernández ${ }^{1 *}$, Yamilé Rabasa ${ }^{1}$, Raquel Montesinos ${ }^{2}$, Dasha Fuentes ${ }^{3}$, \\ Julio Felipe Santo Tomás ${ }^{1}$, Orlando Morales ${ }^{1}$, Yadira Aguilar ${ }^{1}$, Blanca Pacheco ${ }^{1}$, Adolfo Castillo ${ }^{1}$, \\ Ana Maria Vazquez ${ }^{1}$
}

\begin{abstract}
${ }^{1}$ Process Development Direction, INIM, Center of Molecular Immunology, Havana, Cuba; ${ }^{2}$ Center of Genetic Engineering and Biotechnology, Havana, Cuba; ${ }^{3}$ National Center for Laboratory Animal Breeding, Havana, Cuba.

Email: *katiar@cim.sld.cu

Received June $15^{\text {th }}, 2013$; revised July $15^{\text {th }}, 2013$; accepted July $22^{\text {nd }}, 2013$

Copyright @ 2014 Kathya de la Luz-Hernández et al. This is an open access article distributed under the Creative Commons Attribution License, which permits unrestricted use, distribution, and reproduction in any medium, provided the original work is properly cited. In accordance of the Creative Commons Attribution License all Copyrights (C) 2014 are reserved for SCIRP and the owner of the intellectual property Kathya de la Luz-Hernández et al. All Copyright @ 2014 are guarded by law and by SCIRP as a guardian.
\end{abstract}

\section{ABSTRACT}

Racotumomab monoclonal antibody is a murine anti-idiotypic antibody. This monoclonal antibody mimics N-glycolyl-GM3 gangliosides has been tested in several clinical trials Phase I/II for breast, melanoma and non-small cell lung cancer patients as an anti-idiotypic cancer vaccine. The early production process was performed in vivo from mice ascites fluid. This process was transferred to bioreactor-based method at pilot scale followed to the scale-up of the fermentation. In this work we present a comprehensive molecular characterization of racotumomab MAb produced by the two different production scales in order to determine the impact of the manufacturing process in vaccine performance. We observed differences in glycosylation pattern and charge heterogeneity between racotumomab produced in both scales. Interestingly, these modifications had no significant impact on biological activity elicited in chickens. So, changes in primary structure like glycosylation, charge heterogeneity and oxidation did not affect biological activity of the vaccine.

\section{KEYWORDS}

\section{Comparability Studies; Monoclonal Antibody; Cancer Vaccine; Mass Spectrometry}

\section{Introduction}

Racotumomab [1] is a murine anti-idiotype (Ab2) monoclonal antibody (MAb) generated by immunizing BALB/c mice with P3 [2], an Ab1 MAb that specifically recognizes N-glycolylated (NeuGc) gangliosides, sulfated glycolipids, and antigens present in various types of human tumors including those from the lung [3-7]. Our hypothesis was that racotumomab could act as a surrogate of NeuGc-containing gangliosides generating autologous antibodies in the immunized species which react with the Ab2 idiotype and with the NeuGc-containing gangliosides. The aluminum hydroxide-precipitated racotumomab vaccine formulation (racotumomab-alum vaccine) was capable to induce antitumor effects in murine models. These antitumor effects were associated with an

${ }^{*}$ Corresponding author. increment of tumor cell apoptosis, an increment in the number of tumor- or metastases-infiltrating CD4 and CD8 lymphocytes and a reduction of the number of blood vessels [8]. Phases I and II clinical trials have demonstrated the safety and immunogenicity of racotumomabalum vaccination in patients with advanced melanoma, breast and lung cancer [9-12]. From these latter studies, high titer antibody responses to NeuGc-containing gangliosides were measured in the sera of vaccinated patients. For Phases 1 and 2 clinical trials, racotumomab was produced in mouse ascites, a common practice in the 1990's for small scale antibody production.

We first developed a new bioreactor-based process using protein-free media for the production of racotumomab at $10 \mathrm{~L}$ fermentation scale. Later, due to the necessity to increase in production volume, it was necessary to transfer the production process to new facilities 
with a fermentation scale of $41 \mathrm{~L}$ (racotumomab-ST41L). Racotumomab produced from bioreactors (racotumomabST10L and racotumomab-ST41L) has to be bioequivalent to ascites fluid-produced racotumomab (racotumomab-AF) in order to ensure the same effect in the patients. This bioequivalence has to be demonstrated by a set of physicochemical (determination of the molecular weight of the intact molecules and light chains, the sequence of $\mathrm{N}$-terminal peptides, the degree of oxidation by mass spectrometry, and the size and charge of the molecule as determined by dynamic light scattering) and biological methods as required by regulatory authorities for characterization of MAbs [10]. But, because racotumomab is used as an adjuvated vaccine additional characteristics should be taken into account. The first bioequivalence study between racotumomab-AF and racotumomab-ST10L was reported by Machado and colleagues in 2011 [1].

In the present study, we show the detailed molecular and immunological characterization of racotumomab obtained by two different production methods in two scales in order to determine the impact of the manufacturing process in vaccine performance.

\section{Materials and Methods}

\subsection{Materials}

The culture and fermentation of racotumomab hybridoma cell line, purification and alum-formulation processes for racotumomab-ST10L were described by Machado and colleagues previously [13]. The racotumomab obtained from $41 \mathrm{~L}$ fermentation was purified by Protein A affinity chromatography using MAbSelect Sure matrix, followed by anion and cation exchange chromatography $(\mathrm{Q}$ and SP Sepharose FF) and Sepharose G-25 size exclusion chromatography (all from GE Healthcare, USA).

\subsection{Analysis of Intact Molecule, Heavy and Light Chains by Mass Spectrometry}

For mass spectrometry (MS) analysis of intact racotumomab, one lot of racotumomab-ST10L and 3 different lots of racotumomab-ST41L were desalted using solid phase Cleanup C18 Pipette Tips, as recommended by the manufacturer. The desalted samples were mixed 1:1 with sinapic acid solution at $10 \mathrm{mg} / \mathrm{mL}$ and $1.5 \mu \mathrm{L}$ were applied on a MALDI plate and allowed to dry at room temperature.

The mass spectrometer (Axima Performance, Shimadzu, Japan) was operated in the linear mode, at the range of $\mathrm{m} / \mathrm{z} 1000$ - 200,000, the laser power was 85, for the calibration of the mass range of spectrometer in the experiment, ProteoMass Calibration Standards Kit (Sigma, cat. No-1KT MSCAL2) was acquired for 100 profiles per sample and each profile was the average of 10 laser shots.

\subsection{Amino Acid Sequence and Posttranslational Modifications (PTMs) Analysis}

Lyophilized MAbs $(50 \mu \mathrm{g})$ obtained from each process were dissolved in $50 \mu \mathrm{L}$ of $25 \mathrm{mM}$ of Tris-HCl buffer, pH 8.5 with $8 \mathrm{M}$ Urea. After addition of DTT to a final concentration of $50 \mathrm{mM}$, the mixture was flushed with $\mathrm{N} 2$ and incubated for $3 \mathrm{~h}$ at $37^{\circ} \mathrm{C}$. Following this step the sample was cooled to room temperature, acrylamide was added to a final concentration of $100 \mathrm{mM}$ and the mixture incubated for $20 \mathrm{~min}$ in the dark at room temperature.

The samples were diluted 8 times to a final concentration of $1 \mathrm{M}$ Urea. After addition of $1 \mu \mathrm{g}$ trypsin, the mixture was incubated at $37^{\circ} \mathrm{C}$ for $18 \mathrm{~h}$. The reaction was stopped by addition of $2 \%(\mathrm{v} / \mathrm{v})$ TFA in water. The peptide mixture was analyzed directly by MALDI-MS.

Analyses of peptides by MALDI-TOF MS were performed on an Axima Performance mass spectrometer.

(Shimadzu Biotech, Japan) equipped with a 337 nitrogen laser and a collision-induced dissociation (CID) chamber with helium gas. Analyses were carried out in reflector mode $(\mathrm{Mr}<5000)$ with delayed extraction. The instrument was calibrated externally using ProteoMass Peptide Calibration kit (Sigma), low mass gate value of 700 was selected. Data analyses were performed using Shimadzu Biotech Launchpad software (Shimadzu Biotech, Japan).

Digested peptides were purified using CleanUp Pippet Tips C18 (Agilent, USA) as recommended by the manufacturer. Sample was deposited on the MALDI plate by the dried-droplet sample preparation method using acyano-4-hydroxycinnamic acid (CHCA), $10 \mu \mathrm{g} \cdot \mathrm{uL}^{-1}$, in TFA-water-acetonitrile $(0.1: 30: 70, \mathrm{v} / \mathrm{v})$.

\subsection{Analysis of Charge Heterogeneity}

Racotumomab-STs (approximately $100 \mu \mathrm{g}$ each) were diluted five-fold with buffer A (10 mM sodium acetate $\mathrm{pH}$ 5) loaded onto a ProPac10 WCX column (Dionex, Houston, USA) and eluted with buffer B (10 mM sodium acetate, $1 \mathrm{M} \mathrm{NaCl} \mathrm{pH} \mathrm{5).} \mathrm{The} \mathrm{gradient} \mathrm{was} \mathrm{performed} \mathrm{in}$ two steps, from $8 \%$ to $13 \%$ B in $5 \mathrm{~min}$ and $13 \%$ to $20 \%$ $\mathrm{B}$ in 20 min. Protein elution was monitored by absorbance at $280 \mathrm{~nm}$.

\subsection{N-Glycosylation Analysis}

$\mathrm{N}$-glycans were released by digestion with peptideN4-(N acetyl-b-d-glucosaminyl) asparagine amidase $\mathrm{F}$ (PNGase F, BioLabs, Beverly, MA, USA), using the method described by the manufacturer. Briefly, MAbs- Racotumomab were denatured at $100^{\circ} \mathrm{C}$ for $10 \mathrm{~min}$ in $0.1 \%$ SDS, 5\% b-mercaptoethanol. Nonidet P-40 (NP-40) was added to a final concentration of $1 \%$ before enzyme addition. The digestion was carried out at a ratio of $5 \mathrm{U}$ of 
PNGase F per milligram of glycoprotein at $37^{\circ} \mathrm{C}$ for $2 \mathrm{~h}$. The protein was precipitated by adding three volumes of cold ethanol and the mixture was kept at $-20^{\circ} \mathrm{C}$ for 30 $\min$. The oligosaccharides were concentrated under vacuum and subjected to 2-aminobenzamide (2AB) labeling. Oligosaccharides were fluorescently labeled with $2 \mathrm{AB}$ by reductive amination [14]. Briefly, oligosaccharides were dissolved in $5 \mu \mathrm{L}$ DMSO-acetic acid (7:3) containing $2 \mathrm{AB}(0.35 \mathrm{M})$ and $1 \mathrm{M} \mathrm{NaCNBH3}$ and incubated at $65^{\circ} \mathrm{C}$ for $2 \mathrm{~h}$. Excess of fluorophore was removed by $2 \mathrm{~h}$ vertical chromatography on Whatman 3 MM paper using acetonitrile. The paper bearing the oligosaccharide signal (application point) was cut. The oligosaccharides were eluted from the paper by adding double-distilled water $(2 \times 500 \mu \mathrm{L})$. The eluate was filtrated in a syringe through a $0.45 \mu \mathrm{m}$ PTFE filter (Millex-LCR, Millipore) and then concentrated under vacuum.

Normal-phase HPLC (NP-HPLC) of the labeled portion was performed using a TSK-Gel Amide-80 $4.6 \times$ $250 \mathrm{~mm}$ column (Tosoh BioSep, Japan) on a separation module (Merck-Hitachi, Japan) equipped with a fluorescence detector. Labeled N-glycans were separated by a linear gradient of $20 \%$ - $58 \%$ of $50 \mathrm{mM}$ ammonium formiate $\mathrm{pH} 4.4$ against acetonitrile over $152 \mathrm{~min}$ at a flow rate of $0.4 \mathrm{~mL} / \mathrm{min}$. Samples were injected in $80 \%$ acetonitrile. The fluorescence detection was carried out using an excitation wavelength of $330 \mathrm{~nm}$ and an emission wavelength of $420 \mathrm{~nm}$. The elution positions of the Nglycans were determined in glucose units (GU) by comparison with a standard dextran hydrolysate $2 \mathrm{AB}$ labeled (dextran ladder) [16]. The glycosylation was also analyzed by mass spectrometry (MALDI-MS) using an Axima Performance mass spectrometer (Shimadzu Biotech, Japan).

\subsection{Determination of Particle Size Distribution and Surface Charge by Dynamic Light Scattering (DLS)}

DLS analysis used a particle analyzer of dynamic light scattering (DLS) (DelsaNanoC, Beckman Coulter) equipped with a laser diode of $658 \mathrm{~nm}$ wavelength and $30 \mathrm{~mW}$ of power to determine particle size distribution and surface charge on API samples. The acquisition of data determines the particle size distribution which was conducted at $25^{\circ} \mathrm{C}$, with an angle of $165^{\circ}$ in a glass cuvette.

\subsection{Animals}

Leghorn chickens (10 weeks old) were purchased from the Center for Laboratory Animal Breeding (CENPALAB, Havana, Cuba). Animals were housed under conventional conditions with free access to water and food and maintained in accordance with the guidelines stipulated by the Animal Subject Committee Review Board of CENPALAB. Animal studies were performed with approval from CENPALAB's and CIM's Institutional Animal Care and Use Committees.

\section{Results}

\subsection{Mass Spectrometry Analysis}

The mass spectrum of the intact antibody showed a major peak on $148 \mathrm{kDa}$ for racotumomab obtained from both scales. This result confirmed those obtained by polyacrylamide gel electrophoresis (SDS-PAGE) in no reducing condition (Figure 1). Also, the molecular weight of the heavy and light chains were analyzed, confirming the molecular weight of $23-24 \mathrm{kDa}$, in the case of the light chain and $51 \mathrm{kDa}$ for the heavy chain (Figure 2).

\subsection{Amino Acid Sequence and Posttranslational Modifications (PTMs) Analysis}

The racotumomab amino acid sequence remained unaltered during stirred tank fermentation in both scales (Figure 3). Posttranslational modifications detected were heavy chain N-terminal pyroglutamic acid, N-glycosylation and the oxidation of methionine 396.

\subsection{Determination of Particle Size Distribution and Surface Charge by Dynamic Light Scattering (DLS)}

No significant differences in terms of diameter, polydispersity, mobility and zeta potential of racotumomab molecules obtained in both scales were found (Table 1). Values have been reported in the range of $0 \pm 10$ for zeta potential are related to coagulation or flocculation of colloidal particles.

\subsection{Analysis of Charge Heterogeneity}

Figure 4 shows the chromatograms obtained for racotumomab obtained in both fermentation scales. The racotumomab-ST41L presents three "clusters" or groups of four peaks corresponding with 12 charged forms of the antibody, similar to the obtained from $10 \mathrm{~L}$ fermentation. However, the peaks of ractumomab-ST10L are displaced to left in the chromatogram. This result agrees with that obtained by isoelectric focusing where the isoelectric point of racotumomab-41L is slightly more basic than racotumomab-ST10L (Figure 4).

\subsection{Glycosylation Analysis by HPLC and Mass Spectrometry}

Detailed N-glycosylation was investigated by N-glycan mapping of fluorescence-labeled and labeled oligosac- 

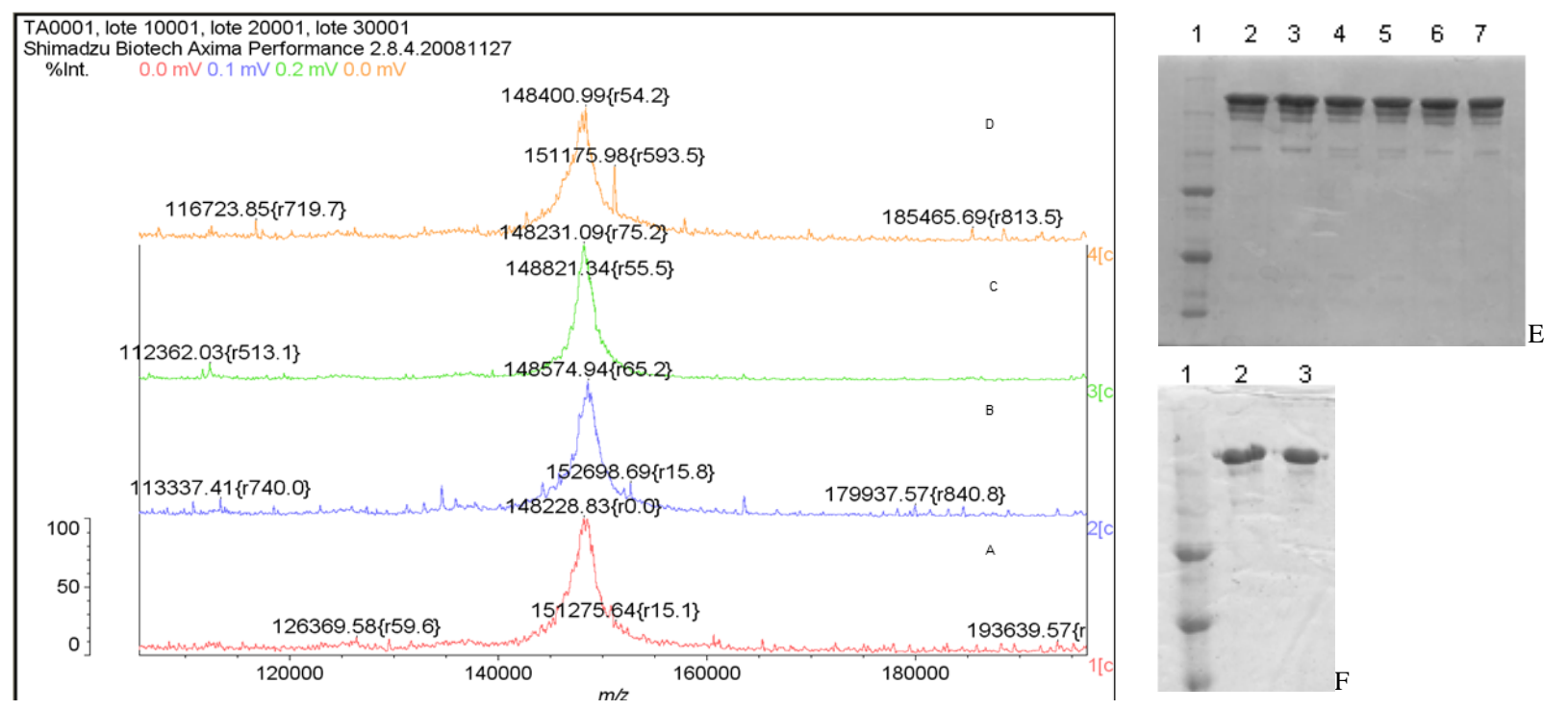

Figure 1. Mass Spectrum of Racotumomab Mab. A: Racotumomab-ST10L, B, C and D: Racotumonab-ST41L. E: SDS-PAGE without reducing Racotumomab Mab. Lane 1: molecular weight standard, lanes 2 and 3: Racotumomab-ST10L, lines 4 - 7: Racotumomab-ST41L (lots 1 and 2), F: SDS-PAGE without reducing Racotumomab Mab. Lane 1: molecular weight standard, line 2: Racotumomab-ST10L, line 3: Racotumomab-ST41L (lot 3).
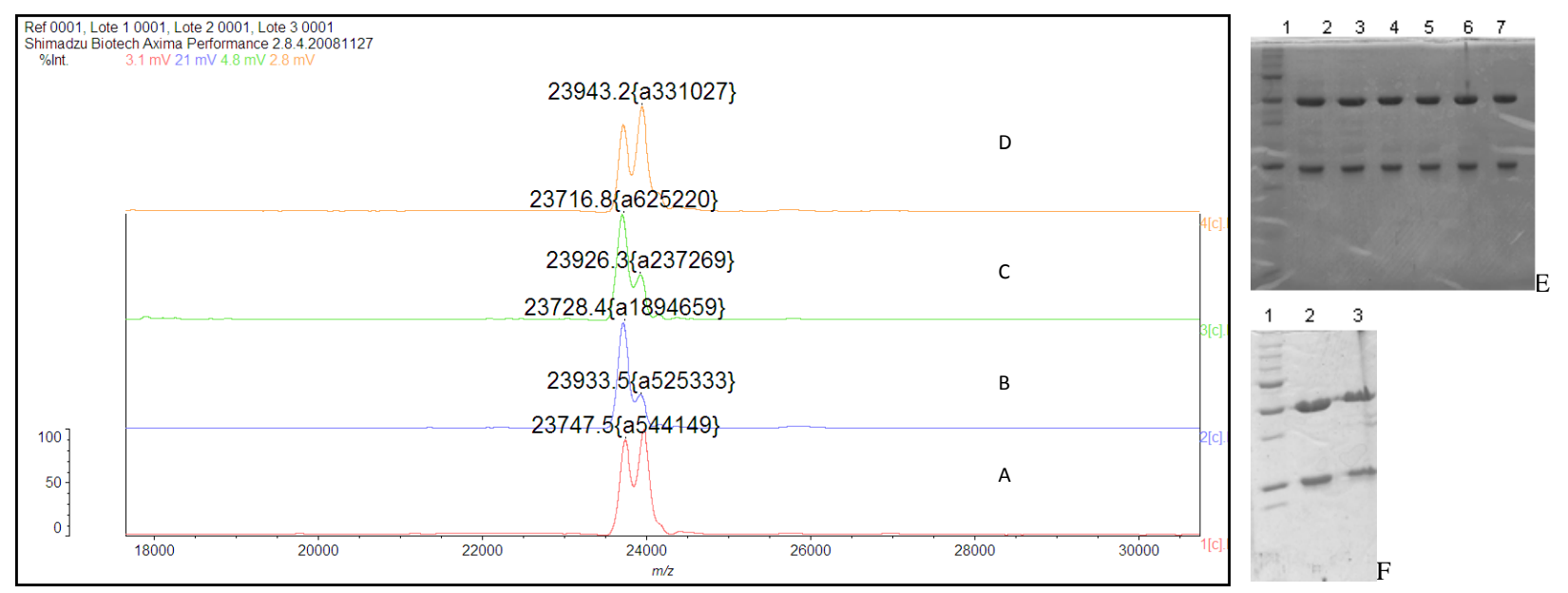

Figure 2. Mass spectra of the light chains of Racotumomab Mab. A: Racotumomab-ST10L, B, C and D: Racotumomab-ST41L. E: SDS-PAGE without reducing Racotumomab Mab. Lane 1: molecular weight standard, lanes 2 and 3: Racotumomab-ST10L, lines 4 - 7: Racotumomab-ST41L (lots 1 and 2), F: SDS-PAGE without reducing Racotumomab Mab. Lane 1: molecular weight standard, line 2: Racotumomab-ST10L, line 3: Racotumomab-ST41L (lot 3).

charides released from the MAbs. The N-glycans identified were core-fucosylated biantennary-complex type oligosaccharides. Minor peaks with higher retention times were determined to be core-fucosylated mono- and disialylated biantennary structures, respectively. Oligosaccharide structures were determined to be similar for both MAb molecules. Six major glycans (G0F, G1Fa, G1Fb, G2F, G2FS1 and G2FS2) were identified.

\subsection{Recognition of Racotumomab in Chicken Sera}

Given the changes found in the isoelectric focusing as- says, charge microheterogeneity and methionine oxidation, it was decided to analyze the reactivity of chickens sera immunized with racotumomab-ST10L against racotumomab obtained from both scales by an ELISA method. Table 2 shows the results obtained for this study. No significant differences were found during the recognition assays for the vaccines obtained from both scales using different dilutions of sera (Figure 5).

\section{Discussion}

Changes in production methods of a biological product may necessitate an assessment of comparability to ensure 


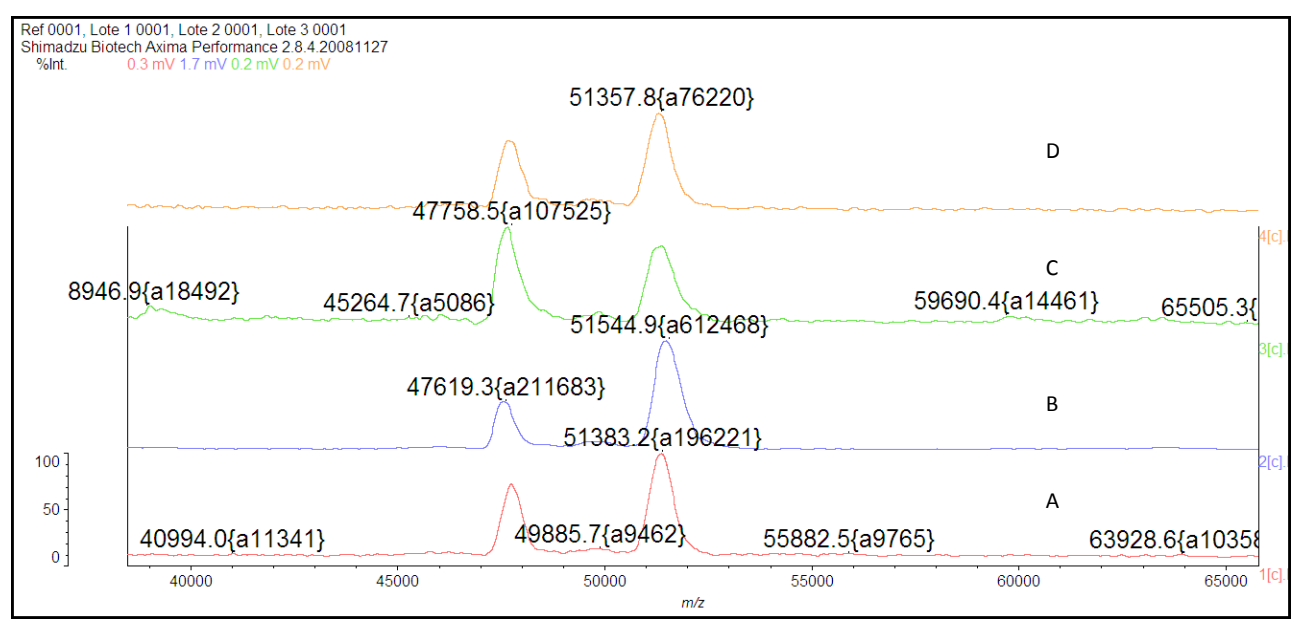

Figure 3. Mass spectra of the Racotumomab Mab heavy chains. A: Racotumomab-ST10L, B, C and D: RacotumomabST41L.

Table 1. Values of polydispersity, particle diameter and zeta potential of Racotumomab-ST10L and Racotumomab-ST41L lots.

\begin{tabular}{ccccc}
\hline Racotumomab & Buffer & Dh(sd) (nm) & IP & Zp(sd) (mV) \\
\hline Racotumomab-ST10L & Tris pH 8 & 12.80 & 0.041 & -7.95 \\
Racotumomab-ST41L & Tris pH 8 & 13.05 & 0.013 & -4.45 \\
Racotumomab-ST41L & Tris pH 8 & 12.05 & 0.018 & -6.78 \\
Racotumomab-ST41L & Tris pH 8 & 11.90 & 0.004 & -7.96 \\
\hline
\end{tabular}

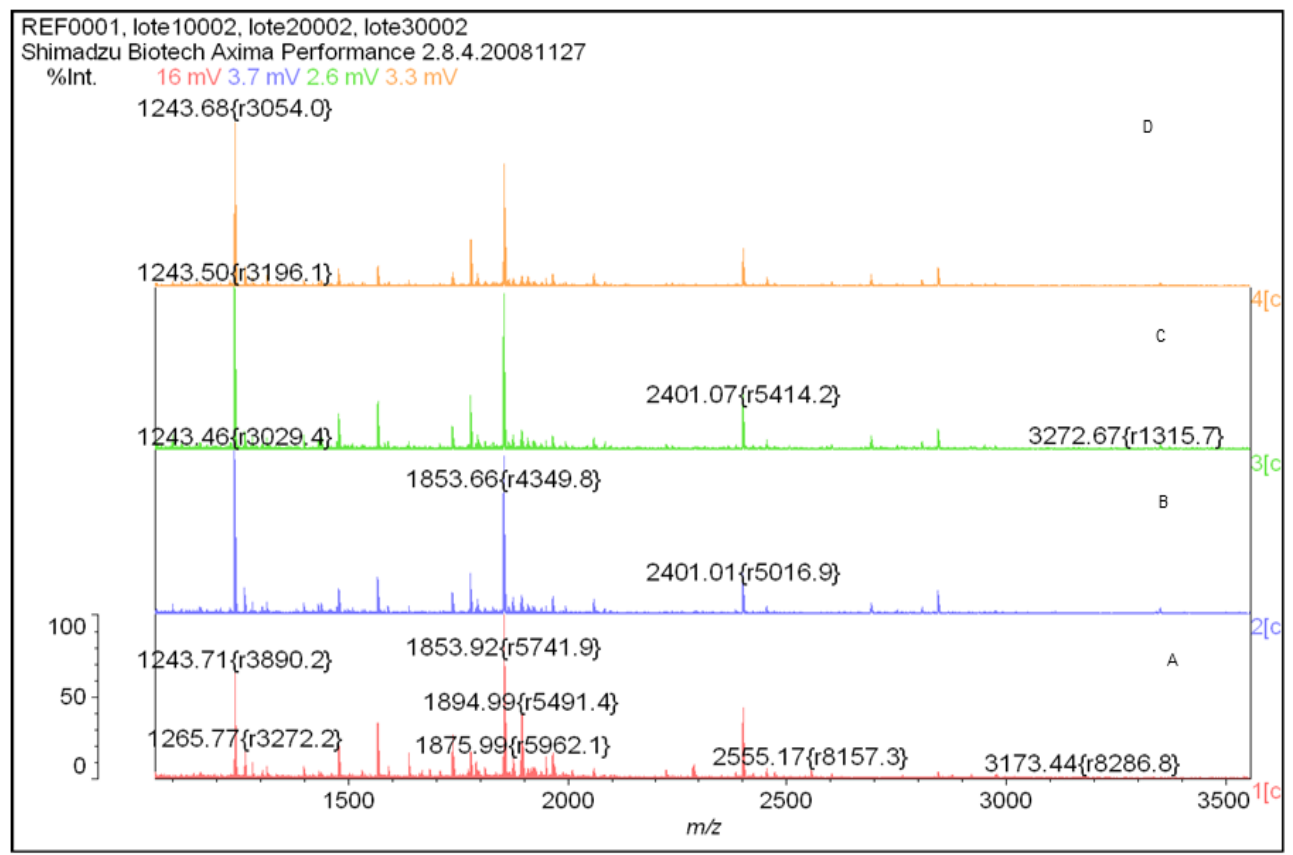

Figure 4. Peptide Mass Fingerprinting of Racotumomab molecules obtained by MALDI-MS. A: Racotumomab-ST10L, B, C and D: Racotumomab-ST41L.

that these manufacturing changes have not affected the safety, identity, purity, or efficacy of the product. Depending on the nature of the protein or the change made during its production, this assessment consists of a hierarchy of sequential tests in analytical testing, preclinical animal studies or clinical studies. Differences in analytical test results between pre- and post-changed products may require functional testing to establish the biological significance of the observed difference. An underlying principle of comparability is that under certain conditions, 
Table 2. Recognition in chicken sera of racotumomab obtaining in both scales.

\begin{tabular}{cccccc}
\hline serum & racotumomab-ST10L & racotumomab-ST41L & racotumomab-ST41L & racotumomab-ST41L & dilution \\
\hline pre-immune & 0.07225 & 0.0815 & 0.075 & 0.0835 & 1.165 \\
chicken 1 & 1.703 & 1.2595 & 1.7255 & 0.665 & $1: 20,000$ \\
& 1.0415 & 0.707 & 1.108 & 0.7705 & $1: 40,000$ \\
chicken 2 & 0.7185 & 0.8375 & 0.8235 & 0.441 & $1: 20,000$ \\
& 0.376 & 0.4725 & 0.4245 & 0.4455 & $1: 20,000$ \\
chicken 3 & 0.4185 & 0.566 & 0.428 & 0.227 & $1: 40,000$ \\
\hline
\end{tabular}

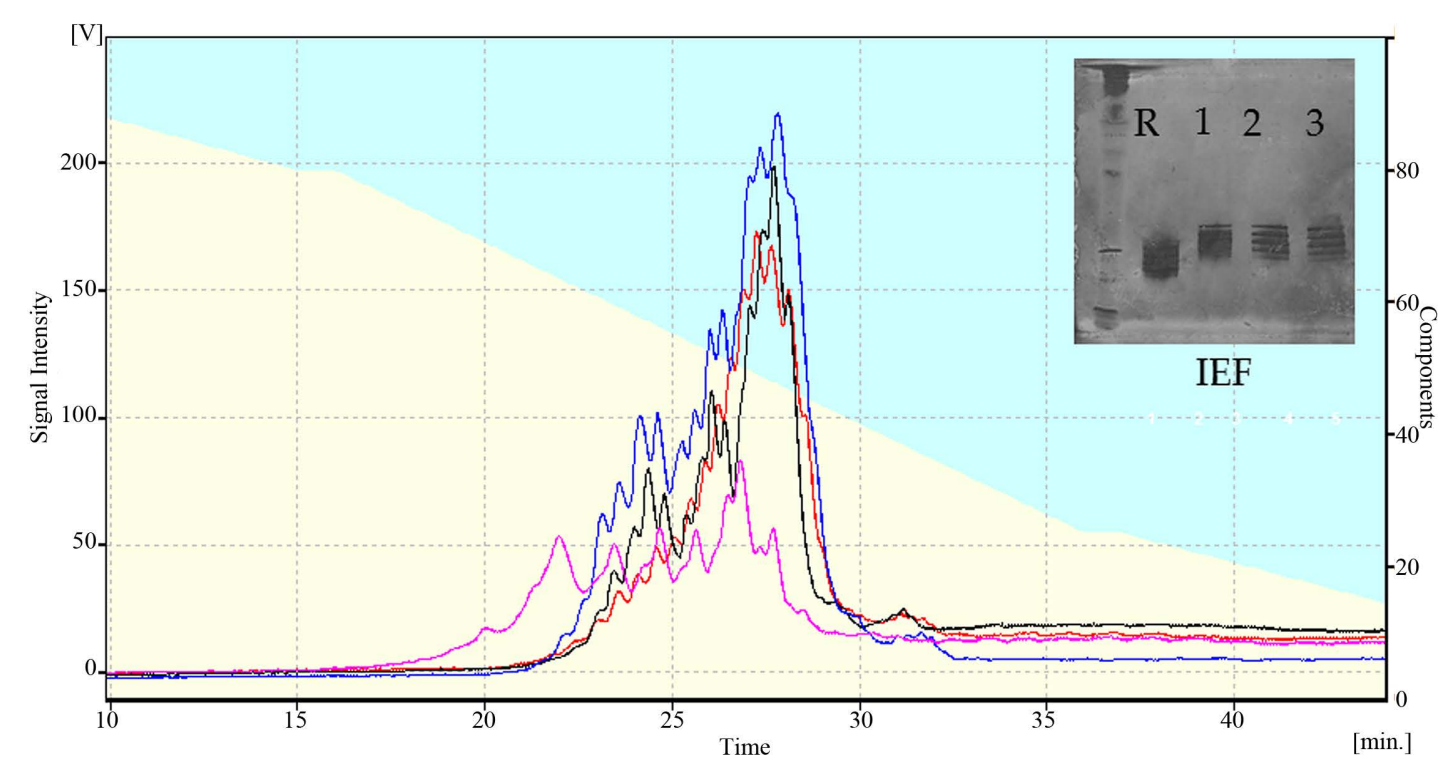

Figure 5. A: Charge Microheterogeneity determined by HPLC-WCX pink: Racotumomab-ST10L, black, red, blue: Racotumomab-ST10L. B: isoelectric focalization, Line 1: isoelectric point standard, line 2: Racotumomab-ST10L, lines 3, 4 and 5: Racotumomab-ST41L.

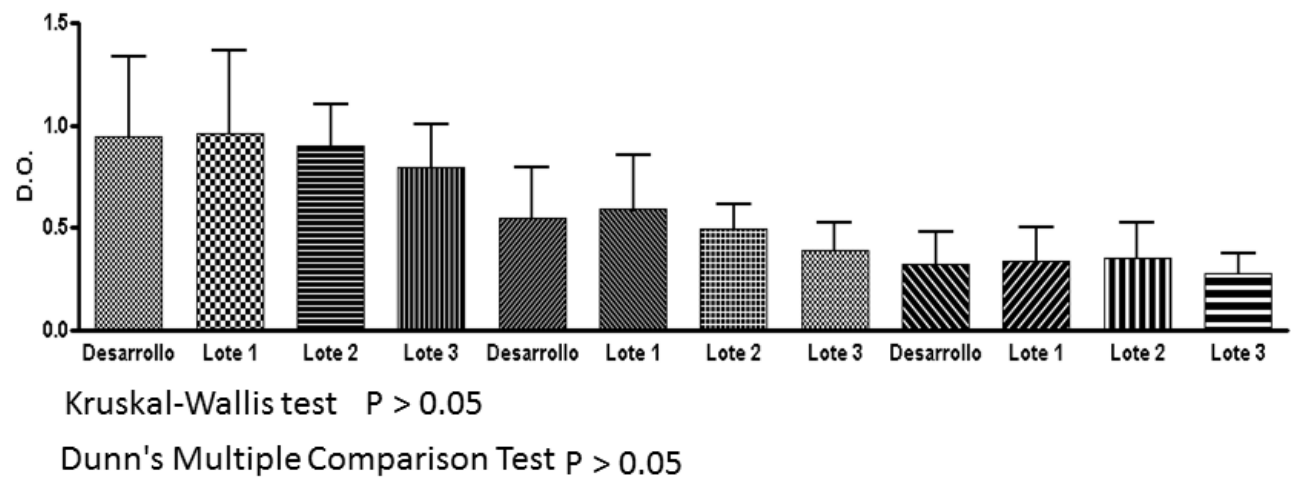

Figure 6. Recognition assay in serum of chicken for the vaccine of Racotumomab/alumina vaccine. Development: Racotumomab-ST10L, lots 1, 2, 3: Racotumomab-ST41L.

protein products may be considered comparable on the basis of analytical testing results alone [15].

It is well known that physicochemical properties of recombinant proteins can be heavily affected during changes in the production process. Thus, it is mandatory to carefully investigate the similarities and differences of therapeutic proteins when the production process has been changed. Comparability must be demonstrated by an array of physicochemical and biological methods as required by the regulatory authorities. Regulatory aspects regarding physicochemical characteristics of idiotypic MAbs used for idiotypic vaccination bear some differences from classic therapeutic MAbs. For idiotypic MAbs, Fc-related functions are not critical for the intended bio- 
logical effect as they are administered adsorbed to alum and via intradermis. Antigen mimicry is restricted to variable region CDRs which are located in Fab [13].

One common posttranslational modification observed in MAbs is a cyclized N-terminal glutamine [16-19] when either the heavy and/or light chain sequences begin with glutamine. This reaction involves the cyclization of the N-terminal amine and the subsequent loss of NH3 (17 $\mathrm{Da}$ ). The gene sequence of the heavy and light chains of many MAbs codes for an N-terminal glutamine, but upon sequencing the $\mathrm{N}$-terminal amino acid is predominantly found as the cyclized pyro-glutamic acid form [20-22]. Regardless the scale, all the heavy chain N-terminal glutamines were found as pyro-glutamic acid, exclusively.

Oxidation of methionine (Met) and threonine (Thr) residues represents a posttranslational modification most commonly observed during changes in the recombinant protein process. Methionine oxidation is a chemical modification known to change the stability and conformation of MAbs through altering $\mathrm{CH} 2$ and $\mathrm{CH} 3$ domain structure $[14,23]$. Oxidation was not observed in racotumomab-ST41L with respect to racotumomab-ST10L where the oxidation in methionine 396 residue was found. The methionine oxidation occurs by the reaction of peroxide or superoxide with the sulfur atom of the amino acid. The finding of the oxidized species can be explained by the formation of reactive oxygen species in certain steps during the production process. The process steps that are most likely to generate reactive oxygen species are those which combine the presence of a metal such as Fe3+, alkaline $\mathrm{pH}$ and dissolved oxygen. Oxidation at Met 396 was not found in the molecule obtained in racotumomab-ST41L, which could be a consequence of changes in the process of fermentation or suppression of the adjustment step at basic $\mathrm{pH}$ in supernatant before the capture step. However, the absence of protein oxidation is an indication of stability and there was not found a connection with the MAbs effector mechanisms.

Deamidation has been shown to be one of the major chemical degradation mechanisms in protein pharmaceuticals during production and storage [24]. Three sites of Asn deamidation were found for racotumomab in both scales, two of these were found in the constant region of the light chain and the other one in the constant region of heavy chain, two of these sites were also observed by Harris et al. [25] studying MMA383 anti-idiotypic antibody.

One of the techniques used during the protein charge analysis is ionic exchange chromatography by HPLC. Cation-exchange chromatography has been introduced to measure charge heterogeneity, in particular caused by lysine variants, more than 15 years ago [25] and now is widely accepted in pharmaceutical analysis. The observed clusters are forms normally associated with the loss of
C-terminal lysine of the heavy chain which is caused by basic carboxypeptidases present in the cell culture. In the case of racotumomab-ST10L, a shift towards acidic isoforms was observed in the MAb, which was also observed in isoelectric focusing. The increase in the acidity of a protein may be related to the presence of oxidized species, an increase of sialylated structures or different processing of the C-terminal Lys.

Future studies are proposed to determine which of the forms correspond to the loss of the C-terminal lysine and with other charged species. Also there were no significant differences in terms of polydispersity and zeta potential of both molecules using DLS (Figure 5).

Glycosylation of proteins is one feature that presents greater variability in the proteins obtained at industrial scale. It has been shown that the availability of nutrients, temperature, fermentation mode, culture time, cell density and age of culture are factors that have a large impact on the type and extent of glycosylation [26,27]. Differences in cell lines or in fermentation processes can produce significant differences in glycosylation pattern [28]. The relevance of glycoforms in biological activity of racotumomab has not yet been determined. The differences found in both scales could be related with differences in processes and time of fermentation as was previously described in the literature [28]. However, these differences do not appear to influence the charge changes encountered in isoelectric focalization and charge microheterogeneity. As racotumomab is intended to be administered as a vaccine, adsorbed to alum and injected subcutaneously the Fc-mediated effector functions do not play a critical role in the biological activity of this MAb. Both products exhibited the same glycan structures attached to Asn297 of heavy chain. As the N-glycan structures of both molecules were identical, and so far none of immunogenic sugar epitopes like alfa Gal-Gal and Nglycolyl sialic acid has been detected, differences in immunogenicity and safety between both racotumomab were not expected.

The differences found in glycosylation profiles and charge heterogeneities are critical parameters that could affect the biological activity of this vaccine. However the biological studies indicated that the vaccines produced with both MAbs have similar recognitions in chickens, so it is an indication that these differences would not constitute critical product attributes (Figure 6). This result confirms that both molecules retain biological activity and immunogenicity. We suggest a study suggests a carefully study in order to analyzed the causes of the changes found in this work.

\section{Conclusions}

In this study, we demonstrated that changes of racotu- 
momab production from ascites to bioreactor and the scale up of the fermentation process generate molecules with a high similarity of point of view of primary structure, but with some different physic-chemical properties. Principal changes were observed in the degree of asparagine deamidation, C-terminal, lysine processing, methionine oxidation and glycosylation pattern, that had an impact on the charge profile of the MAb molecule. The results obtained by DLS showed the absence of aggregates and increase in particle size taking into account the low values of zeta potential observed with the new formulation.

However, the observed changes in physic-chemical characterization did not influenced in the biological activity (immunogenicity and anti-tumoral effect) and the reactivity with sera from chickens and patients previously immunized with racotumomab/alumina, pointing to equivalent clinical effectiveness.

\section{REFERENCES}

[1] A. M. Vázquez, A. Perez, A. M. Hernandez, A. Macias, M. Alfonso, G. Bombino and R. Perez, "Syngeneic AntiIdiotypic Monoclonal Antibodies to an Anti-Neugc-Containing Ganglioside Monoclonal Antibody,” Hybridoma, Vol. 17, No. 6, 1998, pp. 527-534.

http://dx.doi.org/10.1089/hyb.1998.17.527

[2] A. M. Vázquez, M.Alfonso, B. Lanne, K. A. Karlsson, A. Carr, O. Barroso, L. E. Fernández, E. Rengifo, M. E. Lanio, C. Alvarez, J. Zeuthen and R. Pérez, "Generation of a Murine Monoclonal Antibody Specific for N-Glycolylneuraminic Acid-Containing Gangliosides That Also Recognizes Sulfated Glycolipids,” Hybridoma, Vol. 14, No. 6, 1995, pp. 551-556. http://dx.doi.org/10.1089/hyb.1995.14.551

[3] E. Moreno, B. Lanne, A. M. Vazquez, I. Kawashima, T. Tai, L. E. Fernandez, K. A. Karlsson, J. Angstrom and R. Perez, "Delineation of the Epitope Recognized by an Antibody Specific for Nglycolylneuraminic Acid-Containing Gangliosides,” Glycobiology, Vol. 8, No. 7, 1998, pp. 695-705. http://dx.doi.org/10.1093/glycob/8.7.695

[4] M. Alfonso, A. Diaz, A. M. Hernandez, A. Perez, E. Rodriguez, R. Bitton, R. Perez and A. M. Vázquez, “An Anti-Idiotype Vaccine Elicits a Specific Response to N-Glycolyl Sialic Acid Residues of Glycoconjugates in Melanoma Patients," The Journal of Immunology, Vol. 168, 2002, pp. 2523-2529.

[5] E. Neninger, R. M. Diaz, A. de la Torre, G. Suarez, M. R. Gabri, D. S. Alonso, B. Wilkinson, A. M. Alfonso, T. Crombet, R. Perez and A. M. Vázquez, "Active Immunotherapy with Racotumomab Anti-Idiotype Vaccine in Patients with Small Cell Lung Cancer: Report of a Phase I Trial,” Cancer Biology \& Therapy, Vol. 6, 2007, pp. 145150. http://dx.doi.org/10.4161/cbt.6.2.3574

[6] G. Marquina, H. Waki, L. E. Fernández, K. Kon, A. Carr, O. Valiente, R. Pérez and S. Ando, "Gangliosides Expressed in Human Breast Cancer,” Cancer Research, Vol.
56, 1996, pp. 5165-5171.

[7] A. M. Vazquez, M. R. Gabri, A. M. Hernandez, D. F. Alonso, I. Beausoleil, D. E. Gómez and R. Perez, "Antitumor Properties of an Anti-Idiotypic Monoclonal Antibody in Relation to Nglycolylcontaining Gangliosides," Oncology Reports, Vol. 7, 2000, pp. 751-756.

[8] Y. Diaz, A. Gonzalez, A. López, R. Pérez, A. M. Vázquez and E. Montero, “Anti-Ganglioside Anti-Idiotypic Monoclonal Antibody-Based Cancer Vaccine Induces Apoptosis and Antiangiogenic Effect in a Metastatic Lung Carcinoma,” Cancer Immunology, Immunotherapy, Vol. 58, No. 7, 2009, pp. 1117-1128. http://dx.doi.org/10.1007/s00262-008-0634-y

[9] M. Guthmann, M. Castro, G. Cinat, C. Venier, L. Koliren, R. Bitton, A. M. Vazquez and L. Fainboim, "Cellular and Humoral Immune Response to N-Glycolyl-GM3 Elicited by Prolongued Immunotheraphy with an Anti-Idiotypic Vaccine in Hgh-Risk and Metastatic Breast Cancer Patients,” Journal of Immunotherapy, Vol. 29, No. 2, 2006, pp. 215-223.

http://dx.doi.org/10.1097/01.cji.0000188502.11348.34

[10] A. Diaz, M. Alfonso, R. Alonso, G. Suarez, M. Troche, M. Catala, R. M. Diaz, R. Pérez and A. M. Vázquez, "Immune Responses in Breast Cancer Patients Immunized with an Antiidiotype Antibody Mimicking NeuGc- Containing Gangliosides,” Clinical Immunology, Vol. 107, No. 2, 2003, pp. 80-89.

http://dx.doi.org/10.1016/S1521-6616(03)00036-6

[11] V. Segatori, A. M. Vazquez, D. E. Gomez, M. R. Gabri, and D. F. Alonso, "Preclinical Evaluation of Racotumomab, an Anti-Idiotype Monoclonal Antibody to N-Glycolyl-Containing Gangliosides, with or Without Chemotherapy in a Mouse Model of Non-Small Cell Lung Cancer," Frontiers in Oncology, Vol. 2, 2012, p. 160. http://dx.doi.org/10.3389/fonc.2012.00160

[12] A. M. Vázquez, A. M. Hernández, A. Macías, E. Montero, D. E. Gómez, D. F. Alonso, M. R. Gabri and R. E. Gómez, "Racotumomab: An Anti-Idiotype Vaccine Related to N-Glycolyl-Containing Gangliosides-Preclinical and Clinical Data,” Frontiers in Oncology, Vol. 2, 2012, p. 150. http://dx.doi.org/10.3389/fonc.2012.00150

[13] Y. J. Machado, Y. Rabasa, R. Montesinos, J. Cremata, V. Besada, D. Fuentes, A. Castillo, K. R. de la Luz, A. M. Vázquez and M. Himly, "Physicochemical and Biological Characterization of 1E10 Anti-Idiotype Vaccine," BMC Biotechnology, Vol. 11, 2011, p. 112. http://dx.doi.org/10.1186/1472-6750-11-112

[14] H. Liu, G. Gaza-Bulseco, T. Xiang and C. Chumsae, "Structural Effect of Deglycosylation and Methionine Oxidation on a Recombinant Monoclonal Antibody," Molecular Immunology, Vol. 45, No. 3, 2008, pp. 701-708. http://dx.doi.org/10.1016/j.molimm.2007.07.012

[15] A. J. Chirino and A. Mire-Sluis, "Characterizing Biological Products and Assessing Comparability Following Manufacturing Changes,” Nature Biotechnology, Vol. 22, No. 11, 2004, pp. 1383-1391. http://dx.doi.org/10.1038/nbt1030

[16] C. H. Chung, B. Mirakhur, E. Chan, Q. T. Le, J. Berlin, M. Morse, B. A. Murphy, S. M. Satinover, J. Hosen, D. 
Mauro, et al: Cetuximab-Induced Anaphylaxis and IgE Specific for Galactose-Alpha-1,3-Galactose," The New England Journal of Medicine, Vol. 358, No. 11, 2008, pp. 1109-1117. http://dx.doi.org/10.1056/NEJMoa074943

[17] M. Paborji, N. L. Pochopin, W. P. Coppola, J. B. Bogardus, "Chemical and Physical Stability of Chimeric L6, a Mouse-Human Monoclonal Antibody,” Pharmaceutical Research, Vol. 11, No. 5, 1994, pp. 764-771. http://dx.doi.org/10.1023/A:1018948901599

[18] J. Vlasak, M. C. Bussat, S. Wang, E. Wagner-Rousset, M. Schaefer, C. Klinguer-Hamour, M. Kirchmeier, N. Corvaia, R. Ionescu and A. Beck, "Identification and Characterization of Asparagine Deamidation in the Light Chain CDR1 of a Humanized IgG1 Antibody," Analytical Biochemistry, Vol. 392, No. 2, 2009, pp. 145-154. http://dx.doi.org/10.1016/j.ab.2009.05.043

[19] A. Beck, M. C. Bussat, N. Zorn, V. Robillard, C. Klinguer-Hamour, S. Chenu, L. Goetsch, N. Corvaia, A. Van Dorsselaer and J. F. Haeuw, "Characterization by Liquid Chromatography Combined with Mass Spectrometry of Monoclonal Anti-IGF-1 Receptor Antibodies Produced in CHO and NS0 Cells,” Journal of Chromatography B, Vol. 819, No. 2, 2005, pp. 203-218.

http://dx.doi.org/10.1016/j.jchromb.2004.06.052

[20] A. Beck, M. C. Bussat, N. Zorn, V. Robillard, C. Klinguer-Hamour, S. Chenu, L. Goetsch, N. Corvaia, A. Van Dorsselaer and J. F. Haeuw, "Characterization by Liquid Chromatography Combined with Mass Spectrometry of Monoclonal Anti-IGF-1 Receptor Antibodies Produced in CHO and NS0 cells,” Journal of Chromatography B, Vol. 819, No. 2, 2005, pp. 203-218. http://dx.doi.org/10.1016/j.jchromb.2004.06.052

[21] D. A. Lewis, A. W. Guzzetta, W. S. Hancock and M. Costello, "Characterization of Humanized Anti-TAC, an Antibody Directed against the Interleukin 2 Receptor, Using Electrospray Ionization Mass Spectrometry by Direct Infusion, LC/MS, and MS/MS," Analytical Chemistry, Vol. 66, No. 5, 1994, pp. 585-595. http://dx.doi.org/10.1021/ac00077a003

[22] S. Wang, R. Ionescu, N. Peekhaus, J. Y. Leung, S. Ha and
J. Vlasak, "Separation of Post-Translational Modifications in Monoclonal Antibodies by Exploiting Subtle Conformational Changes under Mildly Acidic Conditions,” Journal of Chromatography A, Vol. 1217, No. 42, 2005, pp. 6496-6502.

http://dx.doi.org/10.1016/j.chroma.2010.08.044

[23] G. R. Guile, S. Y. Wong and R. A. Dwek, "Analytical and Preparative Separation of Anionic Oligosaccharides by Weak Anion-Exchange High-Performance Liquid Chromatography on an Inert Polymer Column," Analytical Biochemistry, Vol. 222, No. 1, 1994, pp. 231-235. http://dx.doi.org/10.1006/abio.1994.1478

[24] M. C, Manning, K. Patel and R. T. Borchardt, "Stability of Protein Pharmaceuticals," Pharmaceutical Research, Vol. 6, No. 11, 1989, pp. 903-918. http://dx.doi.org/10.1023/A:1015929109894

[25] R. J. Harris, "Processing of C-Terminal Lysine and Arginine Residues of Proteins Isolated from Mammalian Cell Culture,” Journal of Chromatography A, Vol. 705, No. 1, 1995, pp. 129-134.

http://dx.doi.org/10.1023/A:1015929109894

[26] J. M. Reichert, A. Beck and H. Iyer, "European Medicines Agency Workshop on Biosimilar Monoclonal Antibodies,” MAbs, Vol. 1, No. 5, 2009, pp. 394-416. http://dx.doi.org/10.4161/mabs.1.5.9630

[27] G. Cabrera, J. A. Cremata, R. Valdes, R. Garcia, Y. Gonzalez, R. Montesino, H. Gomez and M. Gonzalez, "Influence of Culture Conditions on the N-Glycosylation of a Monoclonal Antibody Specific for Recombinant Hepatitis B Surface Antigen,” Biotechnology and Applied Biochemistry, Vol. 41, No. 1, 2005, pp. 67-76. http://dx.doi.org/10.1042/BA20040032

[28] Glycosylation Patterns during Fermentation, "Practical High-Throughput Monitoring during Process Development and Manufacturing," Genetic Engineering and Biotechnology News, Vol. 26, 2006, N.8.

http://www.genengnews.com/gen-articles/glycosylation-p atterns-during-fermentation/1516/ 